\title{
Compliance and Adherence to Regulations in the Prescription of Incapacities in Acute Low Back Pain in Tijuana, Mexico
}

\author{
Arambula-Pena MA ${ }^{1 *}$, Bermudez-Villalpando \\ VI', Arambula-Villa G $^{2}$, Antunez-Ruiz VC ${ }^{1}$ and \\ Banuelos-Cisneros $\mathbf{M}^{1}$ \\ ${ }^{1}$ Department of Family Medicine, Baja California \\ Delegation, Mexico \\ ${ }^{2}$ Center for Research and Advanced Studies (Cinvestav- \\ Queretaro Unit), Mexico \\ *Corresponding author: Arambula-Pena Miguel \\ Angel, Department of Family Medicine, Baja California \\ Delegation, Family Medicine Unit \#27 (IMSS), Mexico
}

Received: J anuary 08, 2021; Accepted: February 22, 2021; Published: March 01, 2021

\begin{abstract}
Background: Acute low back pain is an important public health problem in the world that affects economically active people; this condition generates an increase in the use of resources through the payment of subsidies and loss of working days.
\end{abstract}

Aim: The purpose of this study is to know the compliance and adherence to the regulations in the prescription of incapacities in patients with acute low back pain.

\section{Design and Setting: Descriptive cross-sectional study.}

Methods: Descriptive cross-sectional study. A non-probability sampling was carried out in patients with temporary incapacity for work; medical care was evaluated through the Unique Process Evaluation Form (CUEP) for prescription of incapacity to obtain the percentage of compliance through an assessment scale.

Results: Of the 10 items that make up the CUEP, four of them showed results in green, five in yellow and one in red.

Conclusion: Compliance with regulations was partially achieved (73\%). There are areas of opportunity in the continuous improvement of medical attention focused on incapacity, the permanent application of this evaluation instrument will allow to achieve that objective.

Keywords: Low back pain; Incapacity; Medical care

\section{Introduction}

Low back pain is a very common syndrome in the general population. It is the pathology that produces the largest number of years with disability in the world [1]. The Clinical Practice Guide for the management of Low Back Pain of the European COST B13 Program, defines low back pain as pain located between the lower limit of the ribs and the lower limit of the buttocks, the intensity varies according to posture and physical activity, it is accompanied of painful limitation of movement and may be associated with referred or radiating pain [2]. The primary care physician must carry out a specific medical history and physical examination that allows placing the patient with low back pain within one of the following categories accepted by the Spanish and Mexican guidelines [3]: 1) nonspecific lower back pain, 2) low back pain potentially associated with radiculopathy and 3) low back pain potentially associated with specific systemic disease.

Based on the duration of pain, low back pain is classified as acute, pain less than 6 weeks; subacute, pain 6-12 weeks; chronic more than 12 weeks; recurrent, acute low back pain in a patient who has had previous episodes of low back pain in a similar location, with symptom-free periods of three months. Exacerbations of chronic low back pain are not included [3]. The main goal in people with acute low back pain is to reduce or eliminate pain, return to daily activities and work, prevent physical deconditioning, disability, chronicity and avoid incorrect and unnecessary postures; the inability to work is a different concept, it is a compensatory benefit that tries to cover the absence of salary or professional income of a person due to an accident or illness [4].

At the Instituto Mexicano del Seguro Social (IMSS), different strategies have been developed aimed at monitoring and controlling the issuance of Certificates of Temporary Incapacity for Work (CITT), the results of which have substantially influenced the reasoned prescription and the timely payment to the insured of the subsidy generated in their different insurance lines [5]. With the use of information from the department of economic benefits, medical services and the evaluation of the quality of medical care, the timely return to work of workers, compliance with the law, its regulations and current regulations is favored, with the consequent favorable impact on institutional finances [5]. For these reasons, a systematic evaluation of temporary incapacity for work (ITT) is carried out to obtain documentary evidence in the clinical file that normatively supports the issuance of CITT and strengthens the link between the different levels of medical care, identifying areas of opportunity from a medical or non-medical point of view.

The Unique Forms Evaluation of Processes (CUEP) are born as a consequence of the actions described above; the Certificate of Quality
J Fam Med - Volume 8 Issue 1 - 2021

ISSN : 2380-0658 | www.austinpublishing group.com

Arambula-Pena et al. (C) All rights are reserved
Citation: Arambula-Pena MA, Bermudez-Villalpando VI, Arambula-Villa G, Antunez-Ruiz VC and BanuelosCisneros M. Compliance and Adherence to Regulations in the Prescription of Incapacities in Acute Low Back Pain in Tijuana, Mexico. J Fam Med. 2021; 8(1): 1240. 
and Adherence to the Incapacities Prescription Regulations is applied by the clinical department coordinators of the primary care units, where they carry out operational interventions to speed up the care of medical services [5]. There is an "epidemic" of CITT associated with low back pain; in the United States, approximately 10 million incapacities are reported per year due to this cause, while in Mexico it was the seventh cause of absenteeism from work and around $13 \%$ of the total population consulted for acute low back pain [6].

In the family medicine unit \#27 (FMU 27) of Tijuana, low back pain is one of the ten most frequent medical care conditions, for this reason, it is a priority disease that has an impact on the cost of subsidy payments to insured patients disabled by general illness or occupational risk. Therefore, it is important to supervise adherence to institutional regulations through the Unique Process Evaluation Certificate (CUEP) and provide the patient with a timely and quality service; with these actions, the medical care processes are improved and the expenditure for the institution is balanced. The main objective of the research was to know the percentage of compliance and adherence to the regulations in the prescription of ITT in patients with acute low back pain.

\section{Material and Methods}

\section{Study design and population}

A descriptive cross-sectional study was carried out in FMU 27 of the IMSS in Tijuana, Baja California, Mexico, from August 2019 to January 2020. Were included 300 medical records of patients with a diagnosis included according to the International Statistical Classification of Diseases and Health-Related Problems (ICD-10) M-545, which include diagnoses such as back pain, low back pain, acute low back pain, arthrosic low back pain, mechanical low back pain, low back pain due to exertion and low back pain, patients with accumulated days no longer than 6 weeks for general illness or work risk to which CITT codified in the department of economic and social benefits in the FMU 27 was granted.

\section{Variables}

The variables were collected in a standardized data form, data such as sex, occupation and type of incapacity were collected. The medical note was evaluated with the CUEP that measures the following items: 1) Identification evidence, 2) accumulated days of incapacity plus days granted, 3) exceeding probable days of recovery, 4) considering occupation and work activity for ITT, 5) establishes recovery time according to MDA or GPC, 6) identifies IMSS worker or affiliated company, 7) diagnosis according to ICD-10, 8) clinical congruence, diagnosis and stage of the disease, 9) prognosis according to diagnosis and comorbidities and 10) prognosis for labor discharge.

\section{Statistical analysis}

To qualify the CUEP, two phases were considered: 1) qualitative phase: the clinical record was evaluated based on compliance or not with the variable, 2) quantitative phase: the percentage of compliance with each evaluation items was calculated; this percentage is obtained considering the number of cases that meet the criteria of reasoned prescription and adherence to the regulations in the revised notes divided by the total number of cases of temporary incapacities of IMSS workers and affiliated companies in the period, multiplied by 100 . The measurement is made nominal dichotomous and polytomic. The analysis consisted of verifying documentary evidence of compliance with the variable or not, qualifying the value as zero (0) if it does not comply, one (1) if it fully complies and NA if it does not apply. After obtaining the compliance percentage (0-100\%), it was classified according to a color evaluation as follows: $80-100 \%$ good (green), 79-50\% preventive (yellow), less 50\% critical (red).

\section{Ethics}

The study was approved by the Local Committee for Ethics and Health Research number 204, with registration number R-2019204-028. The research was conducted under the General Health Law on Health Research, the Declaration of Helsinki and bioethical principles.

\section{Results}

The sample consisted of 300 files selected randomly. To avoid information biases, the incapacity certificates were issued 100\% electronically, with the initial folio "WV" and their unique continuity number. Most of the medical records were men (54\%) compared to women (46\%). Age showed a range of 18-64 years with a mean of $38.2 \pm 10.4$ years. The most frequent type of identification was INE card in $80 \%(n=240)$ of the cases, $20 \%$ did not have an official identification. The accumulated days of incapacity were distributed as follows: the highest percentage in the groups of 1-7 days (58\%), 8-14 (30\%), 15-21 (7.7\%), 22-28 (2.0\%), 30-35 (1.0\%) and 35-42 (1.0\%). The most frequent work activity was factory employee (67\%), administrative functions (21\%) and other jobs (12\%) (Table 1). In the workers insurance, $58 \%(\mathrm{n}=174)$ were occupational risk and $42 \%$ $(n=126)$ were general illnesses. The prescription of incapacity reflected that $53 \%(n=160)$ were subsequent and $47 \%(n=140)$ were first time. The ICD-10 diagnosis with code M-545 (Table 2) recorded by the doctor at the time of medical attention in the clinical file showed that $49 \%(n=148)$ registered the diagnosis of low back pain, $20 \%(n=60)$ post-exertional low back pain and $16 \%(\mathrm{n}=47)$ acute low back pain.

In the CUEP (Table 3), the "identification evidence" met 77\%, it should have $100 \%$ compliance. "Exceeds recovery days", this variable was met only $42.7 \%, 44.7 \%$ did not apply and $12.7 \%$ was not met, there is no adherence to article 140 of the regulation of social security

Table 1: Baseline characteristics of the population.

\begin{tabular}{|c|c|c|}
\hline Variable & Frequency & Percentage \\
\hline \multicolumn{3}{|l|}{ Sex } \\
\hline $\begin{array}{l}\text { Man } \\
\text { Woman }\end{array}$ & $\begin{array}{l}162 \\
138\end{array}$ & $\begin{array}{l}54 \\
46\end{array}$ \\
\hline \multicolumn{3}{|l|}{ Accumulated days } \\
\hline $\begin{array}{l}1 \text { a } 7 \\
8 \text { a } 14 \\
15 \text { a } 21 \\
22 \text { a } 28 \\
29 \text { a } 35 \\
35 \text { a } 42\end{array}$ & $\begin{array}{c}175 \\
90 \\
23 \\
6 \\
3 \\
3 \\
\end{array}$ & $\begin{array}{c}58.3 \\
30.0 \\
7.7 \\
2.0 \\
1.0 \\
1.0\end{array}$ \\
\hline \multicolumn{3}{|l|}{ Work activity } \\
\hline $\begin{array}{l}\text { Government employee } \\
\text { Factory employee } \\
\text { Construction employee } \\
\text { Administrative } \\
\text { Bachelor's degree }\end{array}$ & $\begin{array}{c}15 \\
201 \\
21 \\
62 \\
1\end{array}$ & $\begin{array}{c}5.0 \\
67.0 \\
7.0 \\
20.7 \\
0.3\end{array}$ \\
\hline \multicolumn{3}{|l|}{ Type of social security } \\
\hline $\begin{array}{l}\text { General illness } \\
\text { Occupational risk }\end{array}$ & $\begin{array}{l}126 \\
174\end{array}$ & $\begin{array}{l}42.0 \\
58.0\end{array}$ \\
\hline
\end{tabular}


Table 2: Frequency of diagnosis according to ICD-10 (M-545).

\begin{tabular}{|l|c|c|}
\hline \multicolumn{1}{|c|}{ Diagnosis (M-545) } & Frequency & Percentage \\
\hline Post-effort low back pain & 60 & 20.0 \\
\hline Acute low back pain & 47 & 15.7 \\
\hline Mechanical low back pain & 12 & 4.0 \\
\hline Lumbar muscle contracture & 14 & 4.7 \\
\hline Lower back pain & 4 & 1.3 \\
\hline Back-lumbago & 15 & 5.0 \\
\hline Low back pain & 148 & 49.3 \\
\hline
\end{tabular}

Table 3: Valuation of the Unique Process Evaluation Certificate (CUEP).

\begin{tabular}{|c|c|c|c|}
\hline & Variable & $\%$ & Value \\
\hline I & Identification Evidence & 77 & \\
\hline II & Days accumulated of prescription plus granted & 55 & \\
\hline III & Spend days of recovery & 87.3 & \\
\hline IV & $\begin{array}{l}\text { Consider Occupation, work activities for ITT } \\
\text { prescription }\end{array}$ & 70.3 & \\
\hline V & Set Recovery time & 73.7 & \\
\hline $\mathrm{Vl}$ & Identify IMSS workers or affiliated company & 80 & \\
\hline VII & Diagnosis according to ICD-10 & 100 & \\
\hline VIII & Clinical Diagnosis congruence, stage of disease & 85 & \\
\hline IX & $\begin{array}{l}\text { Prognosis supported by diagnosis and } \\
\text { Comorbidities }\end{array}$ & 64 & \\
\hline$x$ & Prognosis from discharge to employment & 42.3 & \\
\hline \multicolumn{2}{|r|}{ Total Compliance } & 73.26 & \\
\hline \multicolumn{4}{|l|}{$80-100 \%$} \\
\hline \multicolumn{4}{|l|}{$79-51 \%$} \\
\hline$<50 \%$ & & & \\
\hline
\end{tabular}

medical benefits (RPMSS) [6]; the "days accumulated of prescription plus those granted" $53 \%$ of the cases, there is no adherence to article 151 of the RPMSS, fraction VI, VII and VIII. "Consider the occupation, work activities for ITT prescription", this variable met $70.3 \%$, with $29.7 \%$ lack of attachment; "Establishes recovery time" $73.3 \%$ complied with this item, the doctor has to record in a medical note the reference to the use of prescription support guidelines (Clinical Practice Guidelines); "Identify if he is an IMSS worker or affiliated company", fulfilled $80 \%$ when writing if the patient is an IMSS worker or affiliated company in accordance with procedure 2330-003-008 for the activities of prevention and health promotion services for workers of the IMSS, which improves the opportunity of intervention of this service, favors the vigilance of the worker and offers integral attention to the IMSS workers.

"Diagnosis according to the ICD-10", 100\% complied with the ICD 10 diagnosis since the file is electronic and generated automatically, all with the purpose of providing medical protection by adhering to the sectoral regulations, the medical note is the legal medical document that supports the ITT prescription and offers elements related to the quality of medical care provided; "Diagnostic clinical congruence, stage of the disease", fulfilled $85 \%$ in adherence to NOM004-SSA3-2012, in the medical note the logical relationship between the interrogation, physical examination and comprehensive analysis of paraclinics with the medical judgment of the state of health which guarantees the medical action by adhering to the rules and procedures; "Prognosis supported by diagnosis and comorbidities", 64\% met, the rest do not adhere to NOM-004-SSA3-2012, where in the opinion of the doctor it states the prevention of the emergence, development and termination of the disease, motivated by the diagnosis issued and comorbidities, with written evidence of comorbidities or complications that alter the period of incapacity.

\section{Discussion and Conclusion}

According to the study carried out on the global burden of morbidity with the latest update in 2010, low back pain ranks 7 th among the diseases with the greatest incapacity, compared to the information systems of the FMU 27 where diseases of the musculoskeletal system are positioned in the number 3. Lozano-Ascencia et al., (2013). analyzes the main causes of years of life associated with incapacity where the male sex had a higher percentage, coinciding with our work, since $54 \%$ of the participants they were men. CovarrubiasGómez et al., published that the economically active population that receives medical attention in the Family Medicine Units of the IMSS for lumbar pathology ranges between 20-59 years, in our study the age range was from 18 to 64 years, with a wide range of productive and economically active age who suffer from this disease.

In the accumulated days of incapacity, they were grouped into six age groups, in multiples of seven since a maximum of 7 days are provided in each certificate of incapacity until completing 6 weeks that defines it as acute low back pain, $58 \%$ presented a cumulative of 1-7 days, which reflects being within normal parameters. Of the total number of incapacities generated, $58 \%$ were due to work risks and $42 \%$ due to general illness; $53.3 \%$ were subsequent and $46.7 \%$ for the first time, in the city of Tijuana there are many factories that are one of the main sources of employment for insured claimants served in this unit, for this reason, the amount of work risks is greater than others cities.

Diseases of the musculoskeletal system including acute low back pain have a high percentage of disabled patients; a considerable percentage ends up in incapacity pensions. By losing health, a worker not only loses physical health but also mental health, which has a direct impact on the lack of income for his family, for this reason, the IMSS as an institution that provides social security, provides medical care permanent and economic protection through the subsidy during the period of illness through the issuance of the certificate of incapacity, the treating physician is directly responsible for generating this certificate in accordance with sectoral and institutional regulations, this adherence guarantees the quality of good medical practice.

The evaluations of medical care process identify the areas of opportunity that lead us to improvement the primary care attention in order to be competitive in the health area. Through the results obtained, we can observe that the supervision of the incapacity issuance process is a fundamental piece in the IMSS, good adherence to the established norms and procedures lead us to contain the institutional costs as well as to comply with the indicators assigned to each FMU, through this process the main focus is not lost, which is to restore the health of the workers with the objective of achieving return to work as soon as possible. 


\section{References}

1. Carpio R, Goicochea-Lugo S, Chavez J, Calizaya NS, Collins JA, Henandez $A V$, et al. Guia de practica clínica para el diagnostico y tratamiento de lumbalgia aguda y subaguda en el Seguro Social del Peru (EsSalud). An Fac med. 2018; 79: 351-359.

2. Grupo Espanol de Trabajo del programa Europeo COST B13. Guia de Practica Clinica para lumbalgia Inespecífica.

3. Perez-Irazusta I, Alcorta-Michelena I, Aguirre-Lejarcegui G. Guia de practica clínica de Osakidetza.

4. Vicente-Herrero MT, Terradillos-Garcia MJ, Capdevila-Garcia
Discapacidad e incapacidad laboral en España. Actualización legislativa 2016. Rev Med Inst Mex Seguro Soc. 2018; 2: 84-91.

5. Instituto Mexicano del Seguro Social. Manual de integracion y funcionamiento de los comites para control de la incapacidad temporal para el trabajo, en el ambito normativo, delegacional de unidades médicas de alta especialidad y operativos/COCOITT).

6. Soto-Padilla M, Espinoza-Mendoza RL, Sandoval-Garcia JP, Gomez-Garica F. Frecuencia de lumbalgia y su tratamiento en un hospital privado de la Ciudad de México. Acta Ortopedica Mexicana. 2015; 29: 40-45.

7. Diario Oficial de la Federacion. Reglamento de Prestaciones medicas. 